\title{
Professionalisering van praktijkopleiders via persoonlijke leerplanbegeleiding: evaluatie van een vernieuwend project
}

\author{
S. Schol, P. de Cort, C. Stubbe, D. Vantroyen, N. Vervaeck
}

\section{Samenvatting}

Inleiding: In Vlaanderen is een proefproject uitgevoerd om te kijken of een programma om huisartsopleiders zelf hun leerplannen te laten opstellen en uitvoeren voldeed aan de wensen van de verschillende betrokkenen. Ook is gekeken of de huisartsopleiders klaar zijn voor deze vorm van zelfsturing.

Methode: Per regio $(n=6)$ begeleidde één staflid-facilitator van het Interuniversitair Centrum voor Huisartsenopleiding (ICHO) zes à dertien praktijkopleiders. In totaal waren er 58 deelnemers. De begeleiding van het persoonlijke leerplan bestond uit afwisselende individuele en groepscontacten. Het vierde contact behelsde zowel evaluatie van de persoonlijke vorderingen van de praktijkopleiders als een procesevaluatie van het project. In een semi-gestructureerd interview, aangevuld met een korte vragenlijst, werden de ervaringen van de praktijkopleiders geïnventariseerd. De stafleden-facilitatoren schreven een gestructureerd evaluatieverslag over het projectverloop en de leerplannen van de praktijkbegeleiders werden geanalyseerd.

Resultaten: Zeventien van de 58 praktijkopleiders stelden drie leerplannen op (29.3\%). Drie kwart van alle leerplannen besloeg een periode van meer dan één academiejaar. Tachtig procent van de praktijkopleiders voelde zich door het project meer betrokken bij de opleiding. Praktijkopleiders én begeleiders waren enthousiast over het concept 'persoonlijke leerplanbegeleiding'.

Conclusie: Hoewel de opzet van de evaluatie geen harde conclusies toelaat, is duidelijk dat er verbeteringen in het programma nodig zijn. Er zullen creatieve oplossingen gevonden moeten worden voor het arbeidsintensieve karakter van de begeleiding. Alle betrokkenen waren het er over eens dat deze vorm van 'leren' nieuwe perspectieven opent voor de professionalisering van praktijkopleiders. (Schol S, Cort P de, Stubbe C, Vantroyen D, Vervaeck N. Professionalisering van praktijkopleiders via persoonlijke leerplanbegeleiding: evaluatie van een vernieuwend project. Tijdschrift voor Medisch Onderwijs 2003;22(3):115-123.)

\section{Inleiding}

In de huisartsgeneeskunde wordt in Groot-Brittannië sinds enige jaren gewerkt aan begeleiding van persoonlijke leerplannen en leren met behulp van een portfolio. ${ }^{1-6}$ In het kader van 'continuing medical education' blijken huisartsentutoren het leren met behulp van een portfolio effectiever te vinden dan de gebruikelijke onderwijsvormen, hoewel de opleidingstijd minder efficiënt benut leek te worden. ${ }^{4}$ In een ander onderzoek waren de deelnemers bereid én in staat middels reflectie op de huidige praktijk individuele leerbehoeften op te sporen en hiervoor leerplannen op te stellen. Voor het uitvoeren van de leerplannen koos men voor co-tutorgroepjes waarin niemand als 'expert' werd beschouwd. ${ }^{5}$ Hedley toonde aan dat de kennis en het vertrouwen van de huisartsen toenamen als zij gestructureerd hun opleidingsbehoeften onderzochten en deze vervolgens vertaalden in een opleidingsplan. ${ }^{3}$ Het oor- 
deel van de huisartsen over de persoonlijke leerplanbegeleiding was positief.

Deze gegevens uit de literatuur vormden de aanleiding om in Vlaanderen een 'persoonlijke leerplanbegeleiding voor praktijkopleiders' op te zetten. De ondersteuning van praktijkopleiders is de verantwoordelijkheid van het Interuniversitair Centrum voor Huisartsenopleiding (ICHO). In de Vlaamse huisartsenopleiding worden huisartsen-in-opleiding begeleid door praktijkopleiders huisartsgeneeskunde. De eisen die aan deze praktijkopleiders gesteld worden, staan omschreven in een functieen competentieprofiel. ${ }^{8}$ De eisen hebben betrekking op: (1) de uit te voeren taken, (2) de vakinhoudelijke en agogisch-didactische competenties en (3) de praktijkinrichting en -uitrusting. Het functie- en competentieprofiel biedt de praktijkopleider een kader voor de eigen ontwikkeling als praktijkopleider en voor de geleidelijke groei naar een volwaardige opleidingspraktijk. Het project persoonlijke leerplanbegeleiding is na het eerste jaar geëvalueerd. Hierbij werd een antwoord gezocht op de volgende vragen:

- In welke mate komt het ondersteuningsprogramma tegemoet aan de wensen van de verschillende actoren (praktijkopleiders en stafleden-facilitatoren)?

- In welke mate zijn de praktijkopleiders klaar om hun persoonlijke en professionele ontwikkeling in eigen beheer te nemen (kwaliteit van de leerplannen, vorderingen)?

\section{Methode}

\section{Deelnemers}

In de Vlaamse huisartsenopleiding is per regio één staflid-facilitator van het ICHO verantwoordelijk voor de begeleiding van een zestigtal praktijkopleiders. Er zijn zes regio's. Drie keer per jaar komt men samen in kleine groepjes met collega-op- leiders, de stagecoördinator (de supervisor van de huisartsen-in-opleiding) en een staflid-facilitator. Aan het project persoonlijke leerplanbegeleiding voor praktijkopleiders werd per regio deelgenomen door één groepje van zes tot dertien praktijkopleiders. In totaal ging het om 58 praktijkopleiders en zes stafleden-facilitatoren.

\section{Persoonlijke leerplanbegeleiding}

In het project is gekozen voor een afwisseling van individuele en groepscontacten. Deze keuze is gebaseerd op de vaststelling dat begeleiding die uitsluitend gericht is op zelfsturing, niet effectief is. ${ }^{9}$ Collega's hebben een stimulerend effect op elkaar, hetgeen de motivatie bevordert om werk te maken van de eigen leerplannen. De persoonlijke leerplanbegeleiding bestond uit twee individuele en twee groepscontacten gespreid over één academiejaar. Deze contacten worden nu eerst besproken.

\section{Groepssessie I}

In de eerste groepssessie werden de achtergronden van het project toegelicht. De praktijkopleiders kregen de opdracht om hun sterke en zwakke kanten te analyseren, voorafgaande aan het persoonlijk contact met het staflid-facilitator. Deze analyse werd ingevuld op een kaart voor positiebepaling. Deze kaart is een lijst van doelstellingen die de praktijkopleider helpen het eigen leerproces te sturen. Op de kaart werden één of meerdere punten vermeld waaraan de praktijkopleider wil werken en werd de prioriteit van de leerdoelen aangegeven (figuur 1).

\section{Individueel contact I}

Een zestal weken na de groepssessie bezocht het staflid-facilitator de praktijkopleider. De ingevulde kaart voor positiebepaling werd besproken en op basis hiervan werden drie concrete leerplannen opgesteld (figuur 2). 
Figuur 1. Voorbeeld uit de kaart voor positiebepaling.

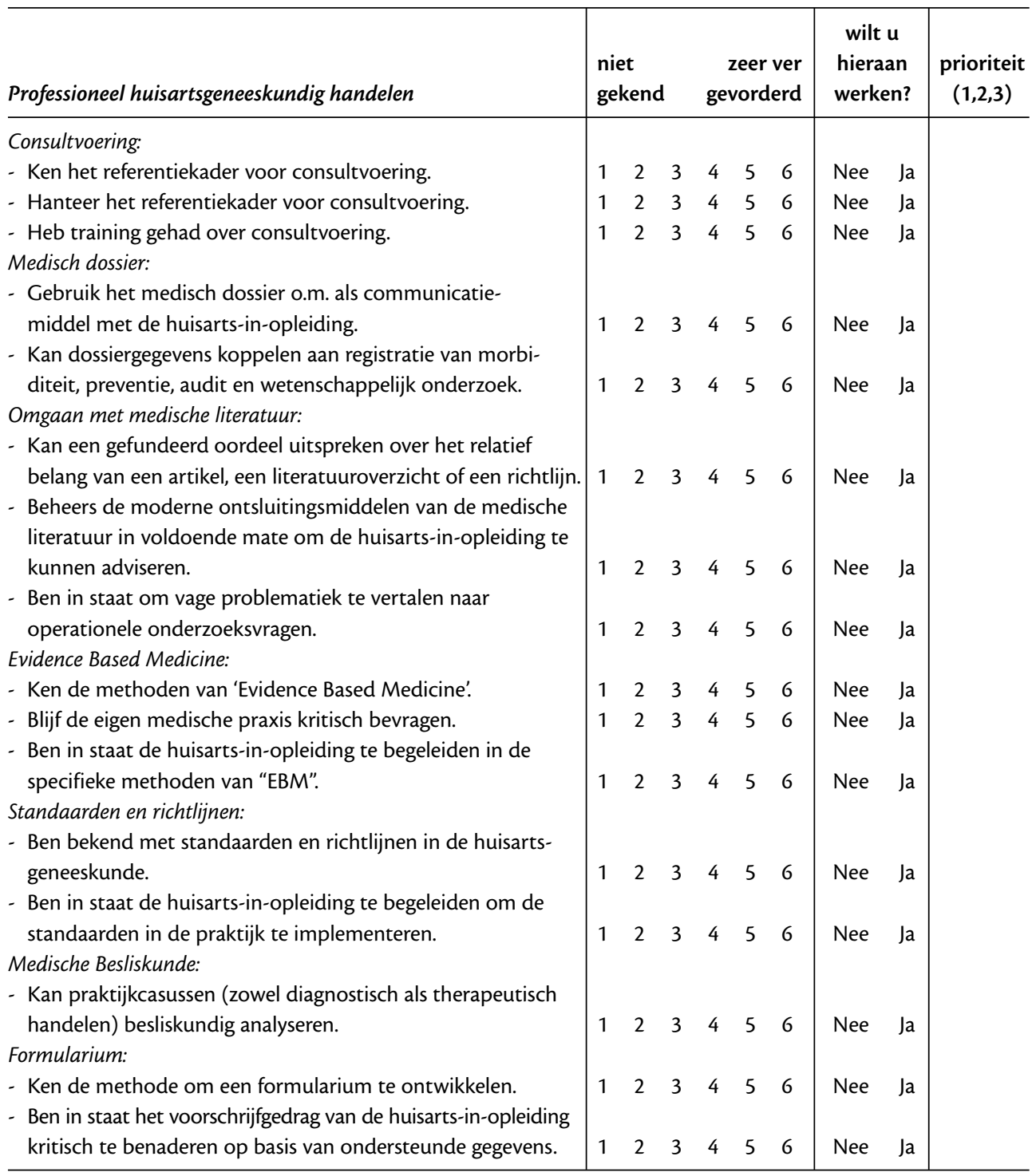

\section{Groepssessie II}

Tijdens de tweede plenaire samenkomst (halfweg het academiejaar) konden de praktijkopleiders ervaringen uitwisselen en elkaar helpen bij het oplossen van problemen. De praktijkopleiders hielden gedurende het jaar een portfolio bij met gegevens over hun leerproces.

\section{Individueel contact II}

Op het einde van het academiejaar was er weer een gesprek van praktijkopleider met staflid-facilitator. In dit gesprek werd gereflecteerd op de uitvoering van de leerplannen en werden conclusies getrokken voor de volgende opleidingsperiode. De nadruk lag op het belonen van geleverde 
Figuur 2. Registratieformulier voor het persoonlijk leerplan van de praktijkbegeleiders.

PERSOONLIJK LEERPLAN NR ...

Naam:

Datum:

Wat is het globale domein waarin ik wil leren?

Hoe ben ik tot deze leerbehoefte gekomen?

Welk resultaat beoog ik met mijn leren?

Welke zijn de specifieke doelen die ik wil bereiken?

Hoe wil ik deze doelen bereiken? (werkplan)

Hoe ga ik mijn vorderingen evalueren?

Hoe ga ik aantonen wat ik heb gedaan om dit plan te realiseren?

Wat is mijn tijdsplanning?

inspanningen en het wegwerken van knelpunten die het realiseren van de leerplannen belemmerden.

\section{Evaluatie-instrumenten}

\section{Semi-gestructureerd interview}

Om het project te evalueren werd als onderdeel van het individuele contact aan het eind van het jaar een semi-gestructureerd interview afgenomen. Hierin deden de praktijkopleiders verslag van hun ervaringen met de persoonlijke leerplanbegeleiding en gaven zij hun visie op de toekomstige implementatie ervan.

\section{Gestructureerde vragenlijst}

In hetzelfde contact werd een korte, gestructureerde vragenlijst afgenomen waarin de praktijkopleider zich anoniem kon uitspreken over de persoonlijke leerplanbegeleiding en de rol van het staflid- 
facilitator. Doordat de vragenlijst anoniem werd ingevuld, konden eventuele sociaal wenselijke antwoorden in het interview ondervangen worden. De vragenlijst was gebaseerd op een lijst van French en Valentine. ${ }^{10}$ We brachten hierin een kleine wijziging aan door drie oorspronkelijk 'dubbele vragen' in verband met leerbehoeften en leerplannen op te splitsen, waardoor de vragenlijst twintig in plaats van zeventien items telde. De oorspronkelijke vijfpuntsschaal werd vervangen door een zespuntsschaal conform de interne afspraak om de schalen in de ontwikkelde vragenlijsten zoveel mogelijk eenvorming te maken.

\section{Gestructureerd verslag}

In een gestructureerd verslag reflecteerden de stafleden-facilitatoren op hun begeleidingsactiviteiten, het draaiboek en de werkinstrumenten. Ook werden knelpunten gesignaleerd en voorstellen gedaan voor verbetering van het project.

\section{Analyse van persoonlijke leerplannen}

Tot slot werden de persoonlijke leerplannen van de praktijkopleiders geanalyseerd. Hierbij werd gekeken naar het aantal leerplannen dat een praktijkopleider had opgesteld, de geplande tijdsduur, de onderwerpen en de uitvoering.

\section{Resultaten}

\section{Semi-gestructureerd interview}

Over het concept van de persoonlijke leerplanbegeleiding was het oordeel van de overgrote meerderheid positief. Ongeveer $80 \%$ van de ondervraagden gaf aan dat zij het gevoel hadden gegroeid te zijn als opleider. Men voelde zich gestimuleerd tot zelfreflectie en beschouwde deze ervaring als een volwassen manier van leren. Het individuele contact met een staflid-facili- tator vond men het nuttigste onderdeel van de begeleiding.

De meningen over de groepssessies waren verdeeld. Desondanks gaven de meeste praktijkopleiders aan behoefte te hebben aan een of andere vorm van ervaringsuitwisseling. Bij de keuze van de leerdoelen lieten de meesten zich vooral leiden door hun persoonlijke ideeën en ervaringen met de huisarts-in-opleiding. Het individuele contact met een staflidfacilitator - waarbij men de kaart voor de positiebepaling een zeer nuttig instrument vond - werd als zinvol gezien. Ook voor het opstellen van de persoonlijke leerplannen had men het meeste baat bij het persoonlijk contact met een staflidfacilitator. In tweede instantie noemde men het contact met collegae of met de huisarts-in-opleiding.

Het verder uitvoeren van de leerplannen werd vooral gestuurd door eigen gedrevenheid en ervaring met de huisarts-inopleiding als continue stimulans hierin. Enkele praktijkopleiders gaven te kennen dat het bij goede intenties was gebleven. Als reden gaven zij vooral aan dat er te weinig ondersteuning was.

Van de stafleden-facilitatoren verwachtten de praktijkopleiders vooral ondersteuning, coördinatie, kennisoverdracht en beschikbaarheid.

Tot slot werd de praktijkopleiders gevraagd wat zij als het belangrijkste leerpunt voor zichzelf beschouwden. Het vaakst genoemd werden de vorderingen met betrekking tot het meer gestructureerd werken aan de eigen opleiding en de vooruitgang in praktische en agogische vaardigheden.

\section{Vragenlijst}

Van de 58 deelnemende praktijkbegeleiders vulden 51 de vragenlijst in. Dat betekent een non-respons van $12 \%$. In tabel 1 
Tabel 1. Score (met standaarddeviatie) op de vragenlijst voor de 'evaluatie van de persoonlijke leerplanbegeleiding' van de praktijkopleiders die de vragenlijst invulden ( $n=51)$ (zespuntsschaal: $1=$ helemaal niet mee eens; $6=$ sterk mee eens).

\begin{tabular}{|c|c|c|}
\hline & $\begin{array}{l}\text { gemiddelde } \\
\text { score }(n=51)\end{array}$ & $\begin{array}{c}\text { standaard } \\
\text { deviatie }\end{array}$ \\
\hline Ik was aanvankelijk enthousiast over het concept van persoonlijke leerplanbegeleiding. & 3.6 & 1.3 \\
\hline Ik was aanvankelijk ambivalent over het concept persoonlijke leerplanbegeleiding. & 3.9 & 1.7 \\
\hline \multicolumn{3}{|l|}{ Ik heb enkel toegestemd in een persoonlijk bezoek van het staflid omdat ik me ertoe } \\
\hline verplicht voelde. & 2.0 & 1.0 \\
\hline Ik vond het gesprek met het staflid een bruikbare en positieve ervaring. & 3.3 & 0.7 \\
\hline $\begin{array}{l}\text { Het gesprek met het staflid hielp mij om mijn gedachten te focussen op mijn leerbehoeften. } \\
\text { Het gesprek met het staflid was tijdsverspilling. }\end{array}$ & 4.7 & 0.9 \\
\hline Ik vond het proces van het verhelderen en in kaart brengen van leerbehoeften nuttig. & 4.8 & 0.8 \\
\hline Ik vond het proces van het opstellen van leerplannen nuttig. & 4.7 & 1.3 \\
\hline Invullen van de kaart positiebepaling was voor mij op geen enkel vlak van enig voordeel. & 2.5 & 1.3 \\
\hline Het opstellen van een leerplan was voor mij op geen enkel vlak van enig voordeel. & 2.1 & 0.9 \\
\hline De kaart voor positiebepaling was te omvangrijk. & 3.3 & 1.4 \\
\hline \multicolumn{3}{|l|}{ Ik vond het gebruiken van de kaart voor positiebepaling eerder beperkend dan } \\
\hline bevorderend. & 2.5 & 1.4 \\
\hline Ik vond het gebruik van leerplannen eerder beperkend dan bevorderend. & 2.2 & 1.0 \\
\hline Het werken met een persoonlijk leerplan was een aangename ervaring voor mij. & 4.6 & 1.1 \\
\hline \multicolumn{3}{|l|}{ Nu ik één jaar gewerkt heb met een persoonlijk leerplan, wil ik dit proces nog even verder } \\
\hline zetten. & 4.7 & 1.3 \\
\hline Ik vond het overbodig om van de opgestelde leerplannen gebruik te maken. & 2.1 & 1.0 \\
\hline $\begin{array}{l}\text { Mijn continue opleiding als praktijkopleider was het afgelopen jaar meer gestructureerd } \\
\text { dankzij de persoonlijke leerplanbegeleiding. }\end{array}$ & \multicolumn{2}{|c|}{ Mijn continue opleiding als praktijkopleider was het afgelopen jaar meer gestructureerd } \\
\hline \multicolumn{3}{|l|}{ Het nieuwe systeem van persoonlijke leerplanbegeleiding is niet de beste manier om de } \\
\hline \multicolumn{3}{|l|}{ Het aanvaarden en gebruiken van een persoonlijk leerplan heeft het afgelopen jaar een } \\
\hline verandering teweeggebracht in mijn medisch handelen. & 4.3 & 1.0 \\
\hline \multicolumn{3}{|l|}{ Het aanvaarden en gebruiken van een persoonlijk leerplan heeft het afgelopen jaar een } \\
\hline verandering teweeggebracht in mijn agogisch handelen. & 4.2 & 1.2 \\
\hline
\end{tabular}

worden de gemiddelde scores op de zespuntsschaal en de standaarddeviaties weergegeven.

De kwantitatieve gegevens uit de vragenlijst wijzen in dezelfde richting als de gegevens uit de interviews. Er waren hoge scores op uitspraken als: 'het werken met een persoonlijk leerplan was een aangename ervaring voor mij' (4.6) en 'nu ik één jaar gewerkt heb met een persoonlijk leerplan wil ik dit proces nog even verder zetten' (4.7). Vooral ook het ontdekken van eigen leerbehoeften en het opstellen van een leerplan werden sterk gewaardeerd. Verder werd ook de manier waarop het staflid-facilitator de praktijkopleider begeleidde in dit project als bevorderend ervaren. Zo scoorde de uitspraak 'ik vond het gesprek met het staflid-facilitator een bruikbare en positieve ervaring' het hoogst met een score van 5.3.

\section{Gestructureerd verslag van de stafleden- facilitatoren}

De eerste samenkomst met de praktijkopleiders werd als goed tot zeer goed erva- 
ren. Het maken van een afspraak voor een bezoek aan de praktijk liep zeer vlot. De stafleden stelden vast dat door één op de vier (15/58) praktijkopleiders de kaart voor positiebepaling niet was ingevuld. In deze gevallen werd eerst naar de reden gevraagd en vervolgens vulde men samen de kaart in. De kaart voor positiebepaling werd ook door de stafleden-facilitatoren als een overzichtelijk, expliciet en goed reflectie-instrument ervaren. Het individuele gesprek met de praktijkopleider nam gemiddeld anderhalf uur in beslag. Het belangrijkste knelpunt in deze gesprekken was het bewaken van de structuur.

De stafleden waren niet tevreden over de tweede groepsbijeenkomst waarin de leerplannen werden besproken. Dit werd toegeschreven aan het onvoldoende 'booster'effect (het versterkende effect van de vergadering). Ook had men het gevoel er niet in te zijn geslaagd het niveau van de groep op te tillen.

Het tussentijds evaluatiegesprek op het einde van het academiejaar werd als de moeilijkste opdracht ervaren. De redenen die men opgaf, waren: de ontgoochelende resultaten van de persoonlijke leerplannen, het individu dat zich in een groepspraktijk verstopt, té grootse projecten met té verafgelegen doelen, de combinatie van kritisch zijn en toch stimulerend en 'last but not least' het overbrengen van negatieve boodschappen. Er was echter grote tevredenheid bij de stafleden over de openheid en het persoonlijk contact met de praktijkopleiders. Andere positieve punten waren het gevoel dat men katalysator was geweest bij het ontwikkelen van leerplannen én dat men een aantal praktijkopleiders had zien 'groeien'.

\section{Analyse van de persoonlijke leerplannen}

In de planning van het project was ervan uitgegaan dat elke praktijkopleider drie leerdoelen (leerplannen) op zou stellen, waarvan er ten minste één betrekking zou hebben op agogisch-didactische vaardigheden. Slechts zeventien praktijkopleiders stelden drie leerplannen op (17/58) en slechts 37 praktijkopleiders formuleerden een agogisch leerdoel (37/58). Tabel 2 geeft een overzicht van de onderwerpen van de leerplannen. Uit de leerplannen was niet af te leiden in hoeverre zij beperkt bleven tot het vergaren van kennis over het opgegeven item en in hoeverre ze resulteerden in concrete implementatie van besluiten en realisaties in de praktijk.

Belangrijke thema's en invalshoeken die reeds verschillende jaren door het ICHO worden aangeboden, kwamen in ongeveer gelijke mate aan bod: kritisch voorschrijven, kritisch lezen, evidence-based medicine, werken met standaarden en programmatische preventie. Het Elektro-

Tabel 2. Overzicht van de inhoud van de leerplannen $(n=113)$.

\begin{tabular}{lr}
\hline thema & aantal \\
\hline & \\
Huisartsgeneeskunde & 75 \\
Evidence Based Medicine & 12 \\
Praktijkorganisatie & 12 \\
Besliskunde & 11 \\
Standaarden - Richtlijnen & 10 \\
Formularium - Kritisch voorschrijven & 10 \\
Kritisch lezen & 10 \\
Preventie & 9 \\
Praktische vaardigheden & 1 \\
& \\
Agogisch-didactische vaardigheden & 37 \\
Leeragenda & 12 \\
Feedback & 9 \\
Consultvoering & 5 \\
Leergesprek & 3 \\
Structuur in opleiding - Attitude als opleider & 3 \\
Evaluatie (tussentijds) & 2 \\
Casusbespreking & 1 \\
Themagesprek & 1 \\
Demonstratie & 1 \\
\hline & \\
&
\end{tabular}


nisch Medisch Dossier kwam in verschillende leerplannen voor: bij preventie en bij praktijkorganisatie. Zeven praktijkopleiders voorzagen in hun agogisch leerplan een video-opname van een consultatie of een leergesprek met de huisarts-in-opleiding, eventueel met feedback door een staflid-facilitator.

Hoewel het project voorzag in een spreiding van de leerplannen over meerdere academiejaren, liep nagenoeg $75 \%$ van de leerplannen (87/113) over slechts één academiejaar. Bij negen leerplannen werd geen datum voor realisatie voorzien.

\section{Conclusie}

De evaluatiegegevens van het project zijn voor een groot deel gebaseerd op opinies en laten niet toe harde conclusies te trekken. Toch is een indruk verkregen van de noodzakelijke voorwaardenscheppende omstandigheden om de persoonlijke en professionele ontwikkeling van praktijkopleiders in eigen beheer te kunnen geven.

Men bleek over het algemeen tevreden over de 'volwassen' manier van opleiden en begeleiden. Ondanks het ontbreken van enige vorm van beloning, werkten de praktijkopleiders enthousiast mee aan dit proefproject.

Uit de evaluatie van de leerplannen komt naar voren dat de doelstellingen van het proefproject niet werden gehaald: slechts een derde van de praktijkopleiders stelde drie leerplannen op, twee derde formuleerde een agogisch doel en de leerplannen waren van beperkte duur. Een belangrijke reden hiervoor is dat de extra activiteiten vrijwillig waren. Het was voor programmamakers, stafleden-facilitatoren en praktijkopleiders een oefening in het vinden van een evenwicht tussen autonomie en controle, tussen sturen en loslaten. Kortom, een experiment in begeleide zelfsturing. Persoonlijke leerplanbe- geleiding is een nieuwe aanpak, die een nieuwe attitude en een nieuwe mentaliteit vraagt. Het blijkt niet eenvoudig om de persoonlijke en professionele ontwikkeling in eigen beheer te nemen. Een grondige voorbereiding is noodzakelijk. Ook toonden de praktijkopleiders een sterke behoefte aan ondersteuning gedurende het gehele proces (frequente contacten, kort op de bal spelen, meer eisend optreden). Geleidelijk aan en afhankelijk van de betrokkene zelf, kan de ondersteuning afnemen. De behoefte aan ondersteuning gold ook voor de facilitatoren. Zij waren tevreden over hun rol als begeleider maar uitten de wens zich hierin verder te kunnen bekwamen.

Alle onderzoekers en deelnemers aan dit project waren het er over eens dat de meest waardevolle elementen van de persoonlijke leerplanbegeleiding uitgebreid zouden moeten worden naar alle praktijkopleiders in Vlaanderen. Een mooie wens waarvoor de randvoorwaarden (tijd, vergoeding, garantie voor carrièrevorming als praktijkopleider) nu in de Vlaamse gezondheidszorg (nog) niet zijn vervuld. Voor een andere belangrijke belemmering, namelijk het arbeidsintensieve karakter voor de stafleden-facilitatoren, werd reeds een aantal modaliteiten ontwikkeld: gebruik maken van moderne communicatiemiddelen, meer nadruk leggen op specifieke groepssessies en het portfolioconcept uitwerken.

\section{Dankbetuiging}

We wensen oprechte dank te betuigen aan de stafleden-facilitatoren en de deelnemende praktijkopleiders voor het laten delen in hun ervaringen met het project en voor hun kritische reflecties en suggesties. In het bijzonder ook dank aan de stafleden dr. Bart van Balen en dr. Jaak Lannoy voor hun medewerking. 


\section{Literatuur}

1. Burrows P, Millard L. Personal learning in general practice. Education for General Practice 1996;7:300-5.

2. Treasure W. Portfolio-based learning pilot scheme for general practitioner principals in south east Scotland. Education for General Practice 1996;7: 249-54.

3. Hedley R. Individual educational plans for GPs. Education for General Practice 1996;7:28-35.

4. Challis M, Mathers NJ, Howe AC, Field NJ. Portfolio-based learning: continuing medical education for general practitioners - a mid-point evaluation. Med Educ 1997;31:22-6.

5. Hibble A, Berrington R. Personal professional learning plans - an evaluation of mentoring and co-tutoring in general practice. Education for General Practice 1998;9:216-21.

6. Snadden D, Thomas M. Community-based curriculum development:what does it really mean? Med Teach 1998;20(3):192-9.

7. Buffels J, Schol S, Leroy DR. Opleidingspraktijken en praktijkopleiders in de huisartsgeneeskunde. Leuven: ICHO-uitgave; juni 2000.

8. Lannoy J, Schol S, Leroy DR. Criteria voor de (her)aanstelling als praktijkopleider. Leuven: ICHO-uitgave; september 2001.
9. Wardekker W, Meijers F, Deen N. Zelfsturing in het onderwijs. Inleiding op het themanummer. In: Comenius. Wetenschappelijk forum voor opvoeding, onderwijs en cultuur. Utrecht: SWP; 1999. p. 289-384.

10. French F, Valentine M. An evaluation of the introduction of personal learning plans for general practitioners in Grampian Region (north-east Scotland). Education for General Practice 2000; 11:165-74

De auteurs:

S. Schol, agoog.

P. De Cort, huisarts.

C. Stubbe, huisarts.

D. Vantroyen, huisarts.

$N$. Vervaeck, huisarts.

Alle auteurs zijn stafmedewerkers van het Interuniversitair Centrum voor Huisartsenopleiding (ICHO) te Leuven.

Correspondentieadres:

Sandrina Schol, Interuniversitair Centrum voor Huisartsenopleiding (ICHO), Kapucijnenvoer 33, blok J, 3000 Leuven, België, tel: +32 16337467 (secretariaat), fax: +3216337480 ,

sandrina.schol@med.kuleuven.ac.be.

\section{Summary}

Context: Based on the literature a programme was developed by the Flemish Interuniversity Centre for Education in General Practice to give GP trainers more responsibility for their personal development as GP trainer. In 2000 we evaluated whether the programme for 'supervised personal learning plans' met the expectations of both GP trainers and facilitators.

Methods: Per region $(n=6)$ one staff memberffacilitator supervised between six and thirteen GP trainers. Fifty-eight trainers participated in the project. The programme consisted of two individual and two group sessions of facilitators and trainers. In the fourth session the progress of the personal learning plans was discussed and the project evaluated. The GP trainers gave their opinions in a semi-structured interview and a brief questionnaire. The facilitators provided further reflections on the project in a report. In addition the learning plans were analysed.

Results: Seventeen of the fifty-eight GP trainers drew up three learning plans (29.3\%). Three-quarters of the plans were limited to one year. Eighty per cent of GP trainers felt more involved in their training than in previous years. Both GP trainers and facilitators showed considerable enthusiasm about the concept of 'supervised personal learning plans'.

Discussion: No hard conclusions can be drawn on the basis of the evaluation. It was clear that there are shortcomings that need to be resolved. Creative solutions will have to be found to make the programme less labour intensive. All those involved in the project agreed that this form of 'learning' opened up new perspectives for the professionalisation of GP trainers. (Schol S, Cort P de, Stubbe C, Vantroyen D, Vervaeck N. Professionalisation of GP trainers through supervised personal learning plans: evaluation of an innovative project. Dutch Journal of Medical Education 2003;22(3):115-123.) 